\title{
Implementation of Outcomes-Based Mathematics Teacher Education Syllabus in Two Colleges of Education in Southern Province, Zambia
}

\author{
Arthur Mungalu* Zanzini Ndhlovu \\ School of Education, The University of Zambia, P.O. box 32379, \\ Great East Road Campus, Lusaka,Zambia
}

\begin{abstract}
The Ministry of Education, Science, Vocational Training and Early Education (MESVTEE) revised the school curriculum as well as the teacher education curriculum in 2013. The revised curriculum for Colleges of Education preparing teachers for Junior Secondary School was rolled out in 2016. The fundamental change was the shift from Objective Based Education to Outcomes-Based Education (OBE). The focus of the study was the Outcomes-Based Mathematics Teacher Education Syllabus (OBMTES). This study sought to assess the implementation of the OBMTES in colleges of education in southern province of Zambia. The study employed a qualitative approach and used a case study design to address the purpose of the study. The target population for the study was 24 lecturers and 120 trainee teachers from which a sample of four lecturers and 40 trainee teachers were selected purposively. Lesson observations, semi-structured interviews and document analysis were used to establish lecturers' practices while Focus Group Discussions (FGDs) (with trainee teachers) were used to establish the trainee teachers' views on lecturers' practices. All data collected was analysed qualitatively by generating themes. The findings indicated that there was lack of alignment between policy and practice lecturers' practices were at abeyance with OBE premises and principles. The lecturers' interactions with students was largely characterised by teacher-centred approaches and the assessments given were not focused on learning. The study recommended that sufficient time and resources should be dedicated towards building capacity among educators regarding the Outcomes Based Education curriculum change.
\end{abstract}

Keywords: Outcome, curriculum implementation, lecturers' practices, Outcomes - Based Education.

DOI: $10.7176 / \mathrm{JEP} / 12-24-08$

Publication date:August $31^{\text {st }} 2021$

\section{Introduction}

The Ministry of Education, Science, Vocational Training and Early Education (MESVTEE) revised the school curriculum and the Teacher Education curriculum in 2013. The revised curriculum in Colleges of Education for preparing teachers of Junior Secondary School teaching was rolled out in 2016. One of the fundamental changes in the revised curriculum was the shift from Objective Based Education to Outcomes-Based Education (OBE). The revised curriculum for Teacher Education was premised on the fact that if teacher educators changed their practices by designing activities that were outcomes-based, the trainee teachers would in turn design and implement similar strategies/lessons in the schools, (MESVTEE 2013). This was particularly important in Mathematics Education as the National Assessment Survey Reports of 1999 to 2012 consistently indicated poor performance of learners in Mathematics at all levels of Education. It was necessary, then, to establish how mathematics lecturers had changed their practices to incorporate OBE premises and principles in their teaching. This was so because the curriculum intent may not always be put into practice by the implementers due to various reasons. As Waxman (2001) stated, the discrepancy between what a curriculum proposal means to its designers and what it means to the teachers who are being asked to use it was a common and continuing problem in curriculum implementation. Muuby (1984) further opined that the teacher sees the curriculum developer's intentions through his or her own perspective so that the viewpoint of the curriculum developer about the nature of learning as well as aims may not be shared by the teacher and are thus interpreted differently or may not even be reflected in the teachers' practices. The implementers (Teacher Educators) adapt the curriculum to suit their feelings, opinions and college environment which might lead to deviation from the expected norm. It was, however, not known whether the OBE premises and principles were being applied in Mathematics classrooms in order to produce Mathematics teachers who were able to teach in an outcomes-based way. Underpinned by the Diffusion of Innovation theory advanced by Rodgers (1995), the study was guided by the following objective; to establish Mathematics lecturers' practices in Mathematics classrooms.

\section{Methodology}

The study employed a qualitative approach to address the purpose of the study. A case study design was used to generate data for analysis to allow for the "investigation of a contemporary phenomenon" (Lecturers' implementation of OBMTES) "within its real life context" (two colleges of education) (Yin 2003). The 
population for the study was government and private colleges of education offering Junior Secondary School Teachers' Diploma Mathematics courses (6). There were twenty-four (24) lecturers of Mathematics Education and one hundred twenty (120) trainee teachers of Mathematics Education in all in these institutions. Trainee teachers were included in the sample to collaborate lecturers' practices in their classroms. A sample of 2 colleges ( 1 government \& 1 private) was selected and 4 lecturers of Mathematics Education ( 2 per college) were included in the study sample. Additionally, 40 student teachers (10 from each of the four classes visited) were picked. Purposive sampling was used to select the two colleges where the study was conducted. To do this, consideration was given to how established an institution was in order to select colleges that could give "rich information for study in depth" (Putton 2002). Besides that, students were asked to volunteer to participate in the FDGs. Data was collected using lesson observations (to note the practices by lecturers in their classrooms), indepth semi structured interviews (to capture direct quotations about lecturers' personal experiences), and document analysis to allow for triangulation of results (Patton 2002). Apart from that, FGDs were done (to establish students' views on lecturers' practices). The process of data analysis included, but was not limited to data organisation, data description and data interpretation (Awoniyi et al. 2011; Putton 2002). The constant comparative data analysis approach was used. Data generated from the field was read carefully and coded (by assigning a word/statement to a category of data). The common codes were grouped into categories which led to themes identification.

\section{Findings and Discussion}

\subsection{Mathematics Lecturers' practices}

\subsubsection{Planning stage}

This section presents results of analysis of the content of the documents (Teaching file) first as these were done or prepared outside the classrooms or lecture rooms before commencement of lectures. The focus was on general planning for daily lessons. In terms of preparation by lecturers we noted the following as indicated in the table 1 .

Table 1. Lecturers' preparation

\begin{tabular}{|l|l|l|}
\hline Preparation activities/practice & Lecturer & Comment \\
\hline $\begin{array}{c}\text { Schemes } \\
\text { Content to be covered }\end{array}$ & T1, T2, T3, T4 & Schemes were prepared by all lecturers \\
Outcomes & T1, T2, T3, T4 & General outcomes indicated \\
Method of teaching & $\mathrm{X}, \mathrm{X}, \mathrm{X}, \mathrm{T}, \mathrm{X}$ & \\
Lesson notes & $\mathrm{T} 1, \mathrm{~T} 2, \mathrm{~T} 3, \mathrm{~T} 4$ & All lecturers indicated content \\
Content & $\mathrm{X}, \mathrm{X}, \mathrm{X}, \mathrm{X}$ & Outcomes not stated. \\
$\begin{array}{c}\text { Outcomes } \\
\text { Ouration of lesson }\end{array}$ & $\mathrm{X}, \mathrm{X}, \mathrm{X}, \mathrm{T} 3$ & Only T3 indicated the duration \\
Activities for students & $\mathrm{X}, \mathrm{X}, \mathrm{X}, \mathrm{T} 3$ & All lecturers planned some examples \\
Examples & $\mathrm{T} 1, \mathrm{~T} 2, \mathrm{~T} 3, \mathrm{~T} 3$ & All lecturers planned for some task \\
Task & $\mathrm{T} 1, \mathrm{~T} 2, \mathrm{~T} 3, \mathrm{~T} 4$ & Only T3 planned relatively more than the \\
Teaching aids & $\mathrm{X}, \mathrm{X}, \mathrm{X}, \mathrm{T} 3$ & others \\
\hline
\end{tabular}

The schemes of work were prepared by all the lecturers that took part in the study. Among other things that were evident in the schemes of work were: content to be covered, general outcomes and specific outcomes. The methods of teaching were not indicated on the schemes of work.

Apart from schemes of work, lecturers prepared lesson notes which mainly showed the content of each lesson from start to end with examples and exercises embedded. The lesson notes were devoid of details such as lesson outcomes, teaching and learning aids, the duration of the lesson and activities for students. Lesson notes were mainly extracted from the teaching modules. When the lecturers were asked why they only prepared notes without key details such as specific outcomes, methods of teaching and teaching and learning materials and activities the common response was that it was not necessary as they had the information in their heads, one of them had this to say:

Lesson notes are a guide during lesson presentation because they contain carefully selected examples that cover the content in depth...for me that is what is important. The way we teach is such that we tell students the intended learning outcomes at the start of the lesson and we use different methods and strategies in a lesson even when they are not reflecting in the notes (Lect. 1, interview - May 2018).

The planning documents showed little evidence of the application of OBE premises and principles. The lesson notes did not reflect the learning outcomes, the teaching methods and strategies for various parts of the lesson as well as TLAs among others. Without documenting such variables, the lecturers were not likely to think about them prior to the lesson, especially TLAs which needed to be organised well before the lesson.

MESVTEE (2013) highlighted that "Planning is important in the work of a teacher and teacher-educator. This 
works as a guide for the effective delivery of lessons and other activities in and outside the classroom." This planning should be such that it takes into account the OBE premises and principles in documents such as scheme of work, lesson plans and/or notes, record of work.

\subsubsection{Lesson execution stage}

Each lecturer was observed three times bringing the total number of observed lessons to twelve. The focus of the observations was the major aspects of a lesson in line with expectations of an Outcome Based Education principles and premises. The practices that were prevalent in the observed lessons by lecturers were; revision of previous work, demonstration by lecturer and demonstration by students. The picture in terms of lesson execution by lecturers was as follows in Table 2

Table 2. Lecturers' practices during lessons

\begin{tabular}{|l|l|l|}
\hline Teacher Activity & Frequency & Comment \\
\hline Whole class & & \multirow{3}{*}{ Lecture approach } \\
\hline -Clarity of focus & 1 & \\
\hline Presenting facts & 8 & \\
\hline -Posing questions & 12 & \\
\hline -Demonstrating & 9 & \\
\hline -Giving task & 10 & \multirow{2}{*}{ Learner centred } \\
\hline -Appropriate or differentiated tasks & 0 & \\
\hline Group work & & \\
\hline -tasks & 3 & \\
\hline Pair work & & \\
\hline -tasks & 3 & \\
\hline
\end{tabular}

The other aspects which are key to the OBME curriculum were rarely practiced or executed.

3.1.2.1 Demonstration by lecturer

The lessons observed showed a pattern of interaction where the lecturer did most of the talking (presenting facts, asking questions and demonstrating solutions) while learners answered lecturers' oral questions; three lecturers out of four used this approach consistently. Generally, students were rarely challenged to investigate mathematical ideas using the prior knowledge; they were simply presented with the concepts by the lecturer as is evident in the excerpt from lesson 2 conducted by lecturer coded 3 below. In this excerpt, $\mathbf{T}$ represents teacher led talk, while $\mathbf{C r}$ represents chorus response by students.

$19 \mathrm{~T} \quad$ We have dealt with the parabola of the type $y^{2}=4 a x$ and concluded that the focus is $F(a, 0)$ as long as Vertex is $(0,0)$. The equation of the directrix is $x=-a$ and the line of symmetry is $y=0$.

$20 \mathrm{~T} \quad$ Now suppose we have a parabola of the type $x^{2}=4$ ay with vertex at origin. Then the focus is $(0, a)$.... Check that it is the opposite of what we did.

$21 \mathrm{~T} \quad$ The equation of the directrix is $y=-a$ and the axis of symmetry is $x=0$. Note: If $a>0$, the parabola opens upwards and if $a<0$, the parabola opens downwards.

$23 T \quad$ Example: A parabola has the focus at $(0,4)$ and its directrix is the line $y=-4$. (i) Write down the equation of the parabola. (ii) Find the equation of the axis of symmetry and the coordinates of the vertex.

$24 T \quad$ Solution... Let $P(x, y)$ be a point on the parabola. The distance from $P$ to the focus $(0,4)$ is the same as from $P$ to the directrix. Using the distance formula, we say that $\sqrt{(x-0)^{2}+(y-4)^{2}}=|y+4| ;$ After squaring both sides, we have $x^{2}+y^{2}-8 y+16=(y+4)^{2}$... Is that right?

$25 \mathrm{Cr} \quad$ Yes sir

$26 T \quad$ Right, from this, we get $x^{2}+y^{2}-8 y+16=y^{2}+8 y+16$ which, after terminating the common terms will give us (Remember that here we can put like terms together and in doing so some terms will be cancelled like $y^{2}$ and 16).

$27 T \quad$ So we shall get $x^{2}=16 y$. Compare our equation $x^{2}=16 y$ with the standard equation $x^{2}=4 a y$, this will give us $4 a=16$ meaning that $a=$

$28 \mathrm{~T} \quad$ Thus, the axis of symmetry is the $y-$ axis, $x=0$ and the vertex is $(0,0)$.

$29 \mathrm{~T} \quad$ Are we alright?

$30 \mathrm{Cr} \quad$ Yes sir

Figure 1. Excerpt from lesson 2 by lecturer coded 3 . 
In line 19, the lecturer gave a synopsis of the previous lesson and then introduced the day's lesson in line 20. Worth noting is that the lecturer gave the focus, the equation of the directrix and the equation of the line of symmetry in line 20,21 and 22 respectively instead of challenging students to attempt to find those variables by relating to the previous work.

Notwithstanding the above observation, the lecturer consistently used pair work in his lessons. While students discussed the given questions in their respective groups, the lecturer took time to see what they were doing and where need arose, he provided mediation for the students. However, the conduct of group work was such that students were not given an opportunity to present their solutions to the whole class and to critique each other's ideas. During the interview the lecturer was asked to comment on the conduct of his lessons. He was quick to mention that:

I am a strong believer in learner centred approach...that is why if you saw I tried to ask them to work in pairs and groups though it wasn't done very well but I always like asking them to think, pair and share (Lect. 3, Interview - May 2018).

The above comment shows that the lecturer was aware that group work and pair work were important but due to constraints of time he did not conclude the session well.

3.1.2.2 Student teachers' views on lecturers' practices

Students indicated that lecturers mainly used lecture method while interactive methods such as discussion were ranking low as shown in the figure 2 .

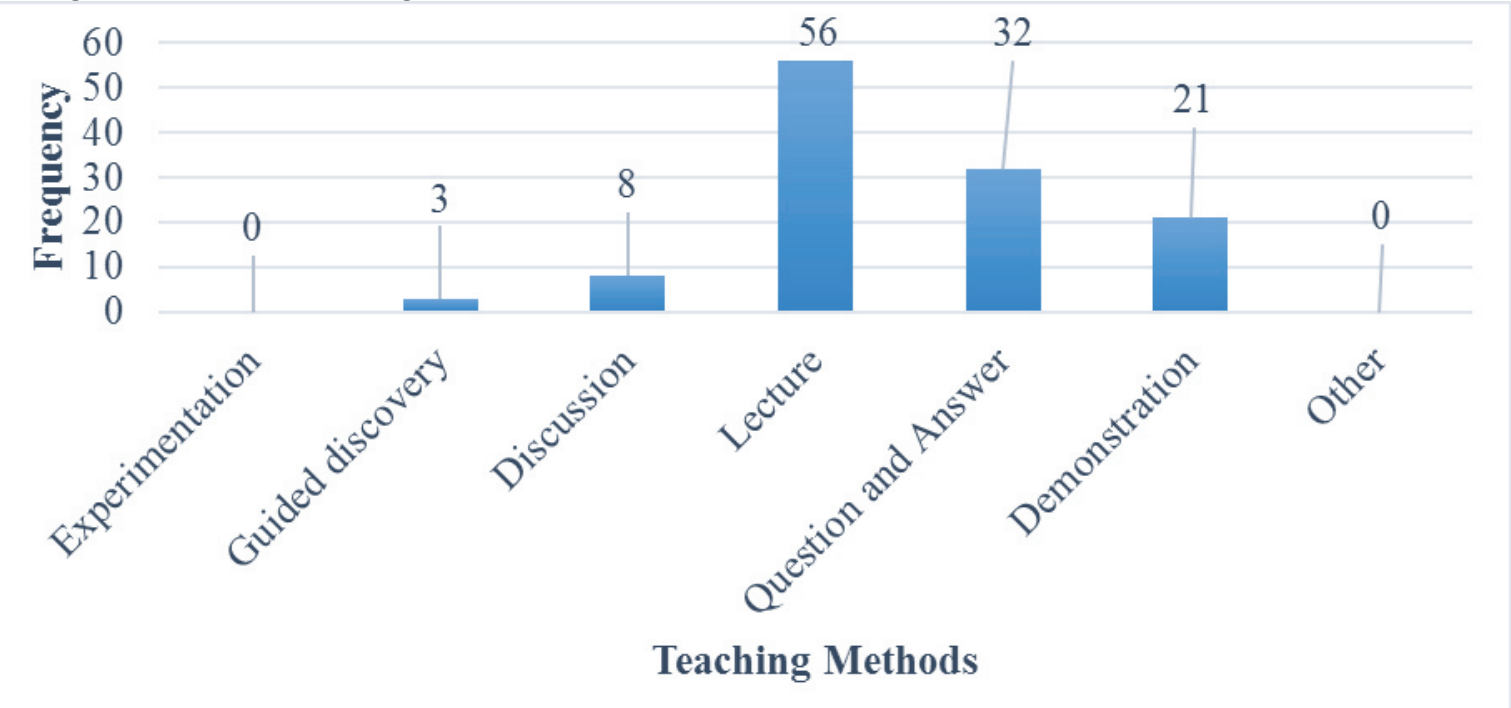

Figure 2. Frequency distribution of methods of teaching

Figure 2 above shows that lecture method was the dominant method of teaching followed by question and answer, demonstration, demonstration, discussion and guided discovery. None of the student teachers chose experimentation as one of the methods used in Mathematics classrooms. One participant response was as follows: Some lecturers make Mathematics simple the way they explain but others it's like they are talking to themselves...others it's like they are only concerned with lecture method just because we are students they will just lecture and say make use of the library (FGD 3, May 2018).

The first factor accounting for lack of alignment between policy and practice was the dominance of teacher centred approaches in the observed lessons. This was confirmed by the findings from FGD where students indicated that the lecture method was the most used teaching method followed by question and answer, demonstration and discussion respectively. Lecturers demonstrated how to solve mathematical problems on the chalkboard and accorded students an opportunity to solve problems on the chalkboard. Moreover, lecturers consistently exhibited traits of transmission mode of teaching in most parts of the lessons where they did most of the talking while students only came in to confirm what the lecturer was saying in response to questions such as "are we alright?" or "is that right?"

The methods of teaching that were deemed to be interactive such as group work were only observed consistently in one case at one college. This provided contexts in which to use mathematical language, negotiate meanings and scaffolding would be applied. However, the version of group work that was exhibited in the classroom discourse was a weaker one as the students were not accorded an opportunity to report their results and critique each other's knowledge.

By and large, what is highlighted above indicated that lecturers were still rooted in the transmission mode of teaching while exhibiting some traits of learner-centred teaching practices. This finding comes in spite of the policy direction that emphasised learner activity during lessons. This finding is not peculiar to this study as 
Ramoroka (2007) found out that educators did not accommodate OBE premises and principles in their practices. Musonda (2009), reviewed the implementation of the Learner - Centered Approach in the teaching of Mathematics at Nkrumah and Copperbelt Secondary Teachers Colleges and established otherwise, that lecturers of Mathematics were implementing learner centred approaches. This discrepancy could be attributed to lack of capacity building of participants in the current study while the participants in the other study were trained through a project that they participated in prior to the study.

3.1.2.3 Inadequate use of teaching and learning resources

The study also sought to establish the use of resources in the classrooms while teaching and learning, it was found that the chalkboard was used the most mainly for illustrating mathematical concepts and for demonstration. What was missing was the incorporation of Information Communication Technology (ICT) resources in the teaching and learning. Notable, among many lessons was the lesson conducted by lecturer coded 2 on the presentation of data on a pie chart. The lesson went on without the lecturer and the students measuring any angle during the process.

When the lecturer was asked which part of the lesson she could have done better, the lecturer had this to say:

Where I could have done better is when dealing with presenting data using a pie chart. I feel it was important for me to come with teaching aids such as a campus and a protractor..., It was difficult to know whether students drew the angles correctly because they did not have instruments as well so I just emphasized to them that they actually have to measure (Lect. 2, Interview - 2018).

The above statement was confirmed during the lesson; students had no mathematical instruments either. The lecturer further indicated that the department had no board instruments like protractor, board ruler and compass for use when teaching such topics.

The findings from lesson observations indicated that other than the chalkboard there was no evidence of use of Teaching and Learning Aids (TLA's) in all the lessons for the four participants. The situation with regards to the use of TLA's in Mathematics lessons was demonstrated in one of the lessons where the concept of a pie chart was taught without using any mathematical instruments (pair of compass, ruler and protractor). It was interesting to note that the lecturer knew the importance of TLA's in mathematics lessons in general and in that lesson in particular despite not having used them.

In that lesson, measuring and drawing angles was the key expected outcome which should have necessitated the use of mathematical instruments considering the fact that reading the protractor is a required skill. The teacher assumed that students were all the same - having the capacity to measure and draw angles contrary to the first premise of $\mathrm{OBE}$ and the principle of design down where the outcome should have dictated the input in the lesson (Spardy 1994).

The policy guiding the implementation of OBMTES suggested that learners should be given expanded opportunities to learn, an ingredient that was missing in the given lesson. In fact, MOE (1996) recognized that:

Quality education requires the availability and use of textbooks and other educational materials. Without these aids to the learning process, effective teaching and learning in the modern sense cannot take place. Suitable materials enable pupils to acquire and apply knowledge, to learn at their own pace and to assess their own progress.

This indicates that teaching aids are valuable tools that lecturers should use to explicate mathematical concepts.

Additionally, the finding did not resonate well with the diffusion of innovation theory, during the initiation stage of the diffusion process, planning for project implementation including materials, resources development is critical. What this entailed was that colleges did not prepare adequately to implement the Outcomes-Based Curriculum by assembling all necessary resources in the Mathematics Department. This finding was not peculiar to this study as Vallente (2016) also reported that there was scarcity of use of teaching and learning resources in Home Economics Lessons, a situation which confirmed that the challenge of lack of resources was a common and continuing problem in curriculum implementation.

3.1.3 Assessment

One common feature in the assessment tool was the lack of authentic contexts; the questions were simply put without any real life situations that required students to figure out and model mathematical sentences before applying appropriate formulae to solve the problem. The questioning techniques did not promote critical thinking; the questions were explicitly given and did not require students to think deeply and critically before solving the given problems. Furthermore, the findings from interviews revealed that lecturers had limited knowledge about Outcomes-Based Assessment (OBA) as deduced from the following comments:

I think on that part I wouldn't say we are responding in line with OBE (referring to assessment)... I may not know whether we are responding in line with that one (OBA) or in line with the old way of doing it (Objective based Assessment) I may not know (Lect. 4, Interview - May 2018).

The comment by lecturer 4 clearly suggested that he was not sure whether he was applying OBE strategies or not. 
Analysis of interview data revealed that lecturers had limited knowledge of OBA. This pointed to a lack of understanding of policy intentions regarding OBA. This lack of alignment could be attributed to inadequate capacity building in OBE. Assessment is an important tool in the teaching and learning process and is used to determine whether teaching and learning have taken place or not. As such, before the teacher sets out to teach a given concept in Mathematics, there may be need to determine students' capabilities as well as challenges through a diagnostic test.

MESVTEE (2013) explained that the following assessment procedures were recommended: Standard-based projects and assignments that require learners to apply their knowledge skills, positive attitudes and values; Clearly defined rubrics (or criteria) to facilitate a fair and consistent assessment of learner's work and; Clearly defined performance targets at key stages of learning. This statement takes cognisance of the OBE premises and principles and acknowledges that not one form of assessment fits all students given their varying needs and the need to provide expanded opportunities for them to succeed. Analysis of assessment tools showed that the problems given to students were mainly of recall and application of formulae with little or no reflection of real life problems which would require students to identify which concept to use in resolving the given problem.

The foregoing indicates that the lecturers lacked knowledge or had inadequate understanding of the tenants of OBE or ignored the curriculum change as espoused in the policy guideline succumbing to 'resistor of change' syndrome. The planning or lack of appropriate planning reflecting OBE tenants was symptomatic of the way they planned their lessons. Planning reflects how a teacher visualises and forecasts the future of the 'what', 'why' and 'how' of the teaching-learning process. In OBE the major focus is outcomes for the students and thus planning should have included the outcomes for the students in a given lesson, the teaching/learning activities, the teaching and learning aids, assessments for learning, and strategies for evaluating outcomes as well as recognition of different abilities of students. The findings showed that to a large extent lecturers did not plan adequately; omitting essential information in their planning, teaching using methods and approaches that did not encourage students' autonomy, not using Teaching and Learning aids, and use of inappropriate assessments.

These findings indicate a lack of alignment between policy and practice as observed by Ramoroka (2007) who established that OBE principles and premises were not accommodated in teachers' practices. The lecturers relied so much on their teaching experience and downplayed the importance of incorporating OBE premises and principles in their planning.

\section{Conclusion and recommendations}

The study has established that lecturers' practices were characterised by planning that was devoid of OBE premises and principles. The lecturers showed inadequate knowledge of OBE principles. This was evidenced by lecturers' consistent use of teacher centred methods in the teaching of Mathematics with traces of learner centred strategies, inadequate application of TLAs and assessment procedures in the teaching of Mathematics which limited students' opportunities to succeed contrary to OBE premises and principles. In view of the findings, the study recommends that government should set aside adequate resources prior to implementation of any innovation so as to equip would be implementers with a vivid understanding of the innovation. Moreover, lecturers with knowledge and competence should be empowered to capacitate others in in-house workshops in order to increase access to information among the implementers. The study suggests that further research be done in other study areas to establish the level of implementation of the Outcomes-Based Curriculum. Additionally, there is need for a study to be conducted particularly on Outcomes-Based Assessment in Mathematics Education.

\section{Acknowledgements}

We would like to acknowledge permission and support given by the Ministry of General Education to conduct this study in the Colleges of Education in Southern Province, Zambia. We also extend gratitude to Institutions and personnel who participated and cooperated in the study.

\section{References}

Awoniyi, S. A., Aderanti, R. A., \& Tayo, A. S. (2011). Introduction to Research Methods. Sango: Ababa Press Ltd.

Bless, C. and Achola, P. (1988). Fundamentals of Social Research Methods: An African Perspective. Lusaka: Government Printers.

Borg, S. (2006). Teacher cognition and language education. London: Continuum.

Creswell, J.W. (2014). Research Design: Qualitative and Quantitative Approaches (4 ${ }^{\text {th }}$ ed). New Delhi: Sage Publications.

Kombo, D.K., \& Tromp, D.L. A., (2006). Proposal and Thesis Writing: An Introduction. Nairobi: Paulines Publications Africa

Manchishi, P.C. (2013). Reforming Zambian Pre-service Teacher Education for Quality Learning. Lusaka: 
University of Zambia Press.

Ministry of Education (1996). Educating Our Future. Lusaka: MOE.

Ministry of Education (1999). Zambia's National Assessment Survey Report of Learning Achievement at the Middle Basic Level. Lusaka: MOE.

Ministry of Education (2001). Zambia's National Assessment Survey Report of Learning Achievement at the Middle Basic Level. Lusaka: MOE.

Ministry of Education (2003). Zambia's National Assessment Survey Report of Learning Achievement at the Middle Basic Level. Lusaka: MOE.

Ministry of Education (2006). Zambia's National Assessment Survey Report of Learning Achievement at the Middle Basic Level. Lusaka: MOE.

Ministry of Education (2008). Zambia's National Assessment Survey Report of Learning Achievement at the Middle Basic Level. Lusaka: MOE.

Ministry of Education, Science, Vocational Training and Early education (2013). Zambia's National Assessment Report 2012: Learning Achievement at the Middle Primary School level. Lusaka: MoESVTEE.

Ministry of Education, Science, Vocational Training and Early education (2013). Zambia Education Curriculum Framework. Lusaka: Curriculum Development Centre.

Munby, H. (1984). A qualitative approach to the study of a teachers beliefs. Journal of Research in Science Teaching, 21 (1), 27-38.

Musonda, A. (2009). Reviewing the Learner-Centred Approach in the Teaching of mathematics at Nkrumah and Copperbelt Secondary Teachers Colleges. A thesis submitted to the University of Zambia in Fulfilment of the requirements for the Master of Education in Mathematics Education.

Nakawa, N (2012). "Growth and Challenges Two Basic Schools Teachers under the Practice of lesson Development Based on Substantial Learning Environment (SLE) in the Republic of Zambia”. Journal of JASME Research in Mathematics Education, 18 (2), 13-21.

Nonaka, T. (2013). "Current Status and Issues of Child-centeredness of Mathematics at Basic Education in Zambia". Journal of JASME Research in Mathematics Education, 19 (2), 45-52.

Olivier, C. (2002). Let's educate, train and learn outcomes - based. Ifafi, Pro Technology, Jul - Dec 2000, 24 (1).

Patton, M. Q. (2002). Qualitative research \& evaluation methods (3rd ed.). Thousand Oaks, CA: Sage.

Ramoroka, N. J. (2007). Educators' understanding of the premises and principles underpinning Outcomes Based Education and its impact on their classroom Assessment practices. A thesis submitted in partial fulfilment of the requirements for the degree of Master of Education in Assessment and Quality Assurance. University of Pretoria, South Africa.

Rogers, E. M. (1995). Diffusions of innovations (4th ed.). New York: The Free Press.

Spady, W. (1994). Outcome-Based Education: Critical issues and answers. Arlington, VA: American Association of School Administrators.

Vallente, J. P. C. (2016). Outcomes-Based Education Integration in Home Economics program: An Evaluative Study. Journal of Education Issues, 2(1), 289-304.

Waxman, H. C. (2001). Research on school-based improvement programs: its implications for curriculum implementation. Education, 15(3), 318-322.

Yin, R. (2003). Case study research design: Design and methods (3rd ed.). California: Sage. 